\title{
EL CLERO DE ALCALÁ DE LOS GAZULES Y SU ENTOR- NO EN EL SIGLO XVIII
}

\author{
Avelina Benítez Barea. \\ Universidad de Cádiz
}

\section{$\underline{\text { RESUMEN }}$}

Por medio del presente artículo pretendemos acercarnos al marco humano y afectivo en el que se desenvuelve la vida del bajo clero rural de Alcalá de los Gazules en el siglo XVIIl. A través de determinadas cláusulas del testamento, advertiremos la relación con su familia y allegados, con sus sirvientes, con los miembros del propio estamento y con sus vecinos en general, encontrándonos con un clero popular, cercano, muy unido a su tierra y a sus gentes para quien las solidaridades familiares son prioritarias y pretende, ante todo, beneficiar y paliar las necesidades de aquéllos con los que convive, en lo que inciden, sin duda, las características del marco geográfico en el que se desarrolla, pues en el ámbito rural en el que nos movemos el clérigo vive rodeado de su familia y de todas las personas que conoce desde siempre, el aporte foráneo es mínimo y el arraigo con la tierra y con los que en ella viven son muy fuertes.

Palabras clave: Bajo clero, entorno rural, familia.

\section{$\underline{A B S T R A C T}$}

By means of this article we intend to approach the human and affective context in which the life of the $18^{\text {th }}$ century low rural clergy of Alcalá de los Gazules develops. Certain clauses of the testament will tell us about the relationship with their families and close relations, with their servants, with the other members of the estate and with the people around them in general. We will find out that this was an ordinary clergy, very close and attached to the town and its common people, and for whom family ties were prior. Their main aim is to benefit those who are close and mitigate their needs, for which the role of the geographic setting is of crucial imprtance, as far as in this rural context the clergyman lives in close contact with his family and the people he has always known, the foreign presence being minimal and the attachment to the land and its inhabitants very strong.

Keywords: Low clergy, rural context, family.

\footnotetext{
' Este trabajo se incluye dentro de otro mucho más amplio que pretende un acercamiento al clero rural gaditano desde diferentes perspectivas, sociales, culturales, económicas, etc., y que abarca el clero de diferentes localidades de la comarca gaditana de La Janda.
} 
El bajo clero ${ }^{2}$ se configura como el sector más popular de toda la clerecía, pues mantiene con su entorno unas relaciones muy próximas. Aunque su status clerical le sitúe en un lugar destacado en el plano cultural, social, e incluso económico, lo cual en muchas ocasiones es más aparente que real, la cercanía, la proximidad a los que le rodean es palpable y evidente. Extraído de sus filas, en condiciones económicas y culturales similares, es difícil que este grupo, aunque catalogado como privilegiado, se mantenga a un nivel superior. Este bajo clero se encuentra en los escalones más bajos de la jerarquía eclesiástica, topado en sus promociones por el propio medio en el que se desenvuelve, tan inmerso en el siglo y tan implicado en las circunstancias personales de cuantos tiene a su alrededor, que su modo de vida, sus actitudes, sus aspiraciones y comportamientos deben más al contexto que a su conciencia clerical en sí.

Es un colectivo compuesto por hombres, hombres que pertenecen a la Iglesia, lo que les imprime un carácter espiritual indiscutible, pero hombres en definitiva, tan unidos al mundo y a lo terreno como otros cualesquiera. Esta dualidad esta conjunción entre lo divino y lo humano que se da en estos hombres, es lo que convierte al grupo y a sus relaciones en algo completamente atractivo e interesante. Si a ello unimos las caracteristicas del enclave geográfico escogido, la villa de Alcalá de los Gazules ${ }^{3}$, bajo el señorío de los Duques de Medinaceli, un lugar cerrado, del interior, con un predominio absoluto del sector primario y un nivel socioeconómico que se puede considerar medio-bajo ${ }^{4}$ y un marco cronológico como el siglo XVIII, siglo agitado y convulso que marca el fín del Antiguo Régimen y en el que se evidencia un cambio de gestos y actitudes en materia religiosa ${ }^{5}$, el resultado es un clero muy integrado en su entorno y mediatizado por él.

Familiares y allegados, sirvientes, vecinos y compañeros de grupo conforman el universo humano en el que se desarrolla su vida: con ellos vive, con ellos trabaja, a ellos sirve. Lo que nos interesa, pues, es conocer sus relaciones con tales grupos, sus afectos, sus preferencias, sus inquietudes.

\footnotetext{
${ }^{2}$ Estado de la cuestión del bajo clero en BARRIO GOZALO, M.:"El bajo clero en la España del siglo XVIII. Estado de la cuestión, problemas y direcciones de la investigación actual", Coloquio Internacional Carlos III y su siglo, tomo I, Madrid, 1988, págs. 793-805.

"Datos de interés sobre la Villa en RAMOS ROMERO, M.: "Alcalá de los Gazules", Historia de los pueblos de la provincia de Cádiz, Cádiz, Diputación, 1983.

${ }^{4}$ DE LA PASCUA SÁNCHEZ, M. J.: Vivir la muerte en el Cádiz del Setecientos (1675-180l). Cádiz, Ayuntamiento, 1990 , pägs. 63-64.

"Para una aproximación al tema ver, entre otros, CHARTIER, R.: Espacio público, crítica y desacralización en el siglo XVIII. Los origenes culturales de la Revolución francesa. Barcelona, 1995; DELUMEAU, J.: El Calolicismo de Lutero a Voltaire. Barcelona, 1973; y LORENZO PINAR, F. J.: Muerte y rifual en la Edad Moderna. El caso de Zamora (1500-1800). Salananca, Universidad, 1991.
} 
Nuestro estudio está basado en un total del 121 documentos 6 , entre los que encontramos 69 testamentos, 12 testamentos en virtud de poder, 29 poderes para testar y 11 codicilos, realizados por 73 clérigos en Alcalá de los Gazules a lo largo del siglo XVIII.

En ellos hemos profundizado en las cláusulas correspondientes a Legados, Albaceas, Herederos y Deudas, cláusulas que nos parecen muy significativas para nuestro objetivo, acercarnos a la dimensión social y humana del bajo clero rural, pues los albaceas nos hablan de la confianza, los herederos y legatarios de la obligación, el cariño, la gratitud y la fidelidad, además de darnos pistas sobre la convivencia con determinadas personas; y las deudas, por último, al margen de la trayectoria económica de estos hombres, nos sirven para averiguar el tipo de relaciones económicas que mantenían con los que les rodeaban y si esa situación de superioridad que se les supone se plasmaba en el terreno económico a través de ciertas actividades como el comercio o los préstamos. Además, nos parecen lo suficientemente representativas dentro del testamento como para que sean útiles, pues en todos o en la gran mayoría de ellos aparecen.

De esta forma, en el $74 \%$ de los testamentos del período se realizan legados, por el $68,4 \%$ de los clérigos tratados. El clero no tiene herederos forzosos, por tanto posee la libertad de poder utilizar los legados como medio para beneficiar a cuantas personas desee, y así lo hace, a veces en un número considerable, como tendremos ocasión de comprobar. Como en otras zonas de nuestra geografía, este grupo destaca tanto en la generalización de su práctica como en el número de mandas realizadas. No obstante, el hecho de habitar en un entorno rural también condiciona la incidencia de dicha práctica.?

Las preferencias se inclinan por dejar a los legatarios los medios de subsistencia asegurados a través de los bienes más preciados en una economía de base eminentemente agropecuaria, como es la alcalaína. Así, predominan las mandas de ganado, ganado vacuno, principalmente; dinero, un bien útil para cubrir cualquier necesidad; ropa, mantos y sayas o dinero para comprarlos; muebles y menaje y partes de casa, cuartos vitalicios, en su mayoría, pues rara vez se dejan casas completas, para sirvientas y parientas huérfanas, doncellas o viudas, que viven con ellos y les asisten.

\footnotetext{
- Documentos que se hallan en el Archivo Histórico Provincial de Cádiz, en adelante A.H.P.C., en la Sección Protocolos de Alcalá de los Gazules.

' GARCÍA FERNÁNDEZ, M.: Herencia y patrimonio familiar en la Castilla del Antiguo Réginen (1650-1834). Efectos socioeconómicos de la muerte y la partición de bienes. Valladolid, Universidad, 1995 , pág. 148.
} 
La relación por sexos nos indica que las mujeres aparecen como legatarias en más ocasiones que los hombres, aunque la diferencia no es excesiva, un $56,9 \%$ de mujeres frente a un $43 \%$ de hombres.

Por su parte, los albaceas están presentes en el 100\% de los testamentos, nombrándose un total de 269; mientras que los herederos, también contemplados por todos los testadores de la muestra, suman 176. En el campo del albaceazgo se aprecia el predominio absoluto de los hombres sobre las mujeres, siendo los porcentajes de ambos $82,5 \%$ y $17,4 \%$, respectivamente; en tanto que en el de la herencia la tendencia es la inversa, aunque más atenuada, siendo los porcentajes de mujeres y hombres, respectivamente, el $57,1 \%$ y el $34,8 \%$.

Por último, en lo referente a deudas, las acreedoras se reflejan en el $58 \%$ del número total de testamentos, redactados por el $57,5 \%$ de los clérigos tratados, mientras que las deudoras se registran en el $69,1 \%$ de los testamentos, pertenecientes al $56 \%$ del número total de clérigos, declarándose 159 acreedores y 299 deudores en total. Las deudas acreedoras son principalmente debidas a arrendamientos, en especial de las tierras en las que tienen sembradas sus sementeras, pues estos clérigos son más ganaderos que agricultores, ya que no suelen presentar muchas tierras entre sus propiedades. Deudas por préstamos, géneros y mercaderías fiadas a mercaderes y artesanos del lugar, censos, salarios, alquileres y compras aparecen con unos porcentajes menores respecto a las primeras.

En cuanto a los deudores, los préstamos ${ }^{8}$ a vecinos, los arrendamientos sobre casas de sus capellanías y memorias y los de sus propios animales para la labor de tales vecinos suelen ser los motivos principales. A mayor distancia tenemos los censos, alquileres y tributos.

Según se desprende de los datos personales que se aportan en los testamentos, el perfíl ${ }^{9}$ que ofrecen estos clérigos es el siguiente:

\footnotetext{
${ }^{\text {R }}$ En el capítulo de los préstamos a vecinos destaca D. Juan de Jerez Jiménez, presbítero, el cual declara 49 deudas por este motivo, que oscilan entre los 15 reales de vellón y los 450 , además de los préstamos de grano. El volumen de estos préstamos nos indica una economía saneada, unas propiedades importantes y una situación entre sus convecinos de privilegio, siendo la persona a la que todos acuden cuando tienen una necesidad. En ocasiones estas deudas son perdonadas, si no totalmente, si al menos una parte de las mismas, con la condición de repartir su importe o comprar ropa para los hijos de los deudores. A.H.P.C., Sección Protocolos de Alcalá de los Gazules, Libro 161, folios 55-69 y 85 87.

"Prototipo del perfil del bajo clero rural, Vid, entre otros, CANDAU CHACÓN, M. L.: El clero rural de Sevilla en el siglo XVIII, Sevilla, Caja Rural, 1994; y SÁNCHEZ GONZÁLEZ, R.: "El clero rural del arzobispado de Toledo en el seiscientos: distribución, formación y conducta. Hispania Sacra, Vol. XLVI, (1994), págs. 427-447.
} 
Debido a la fuente utilizada, nos encontramos con un clero de edad elevada, compuesto, en su mayoría, y por este mismo motivo, por presbíteros, la mitad de los cuales son beneficiados y algunos poseen, además, algún cargo importante dentro de la jerarquía eclesiástica, la jerarquía a la que se puede aspirar dentro del ámbito rural que nos ocupa, se entiende, apareciendo algún Vicario o Comisario del Santo Oficio. En la mayor parte de los casos testan enfermos, lo cual no difiere en gran medida de lo que hace el resto de sus convecinos ${ }^{10}$, de enfermedades que se presuponen avanzadas, pues en bastantes ocasiones les impiden la firma del documento.

Respecto a su naturaleza y vecindad, casi todos los que la detallan se declaran naturales y vecinos, hijos de padres naturales y vecinos, cuando se especifica la filiación.

La aparición en los testamentos de parientes colaterales de segundo y tercer grado nos demuestra el nivel de endogamia existente en estos pueblos pequeños y concretamente el de los clérigos tratados, con familias extensas afincadas en el lugar con una anterioridad de un par de generaciones, al menos; tener hermanos y sobrinos en una localidad implica la vecindad de padres y hermanos; tener primos y tíos retrotrae esa condición hasta los abuelos y tener parientes indeterminados puede retrotraer la condición aún más allá.

Por último, su nivel de instrucción se advierte muy bajo, prueba de ello es que sólo aparecen 3 licenciados en toda la muestra; lógicamente, dos de ellos poseen algún cargo. No obstante, aunque no tengan estudios son los que mayor nivel cultural poseen en un mundo completamente iletrado, por lo que serán la referencia de sus vecinos y los que se encarguen de sus asuntos. ${ }^{11}$

\section{EL ENTORNO DEL CLÉRIGO}

Como hemos indicado en la introducción, familia y allegados, sirvientes, vecinos y compañeros de grupo conforman el universo humano en el que se desarrolla la vida del clérigo. El estudio más exhaustivo de las cláusulas citadas, en función de dichos grupos, arroja los siguientes resultados:

I" DE LA PASCUA SÁNCHEZ, M. J.: op.cit., pág. 43.

${ }^{11}$ D. Cristóbal Muñoz de Medina, presbítero beneficiado, cura más antiguo y Comisario del Santo Oficio, realiza un poder mancomunado con su hermano con motivo de un viaje a Madrid, a dependencias del Consejo de la villa y del común de sus vecinos. A.H.P.C., Sección Protocolos de Alcalá de los Gazules, Libro 276, 2 folios. 


\section{Familia y allegados}

Este grupo, en el que se incluyen tanto los familiares propiamente dichos como todas aquellas personas con las que el clérigo guarda una relación cuasifamiliar, basada en el cariño y la protección, acapara el $54,2 \%$ de los legados ${ }^{12}$.

Las soorinas, bencficiarias del $29,7 \%$ del total del grupo, predominando, en los casos en que se declara el estado, las doncellas, huérfanas y viudas; seguidas de los sobrinos, entre los que encontramos también algunos huérfanos y una séptima parte de eclesiásticos, que perciben el $28,2 \%$, son los principales legatarios familiares del clérigo. Ellos son, además, los que mayor variedad de legados reciben, uno poco de todo lo necesario para sobrevivir: casa, dinero, ganado y muebles, sobre todo las sobrinas doncellas o viudas.

Con porcentajes muy inferiores, pero similares, los hermanos, entre los que aparece sólo un eclesiástico; las primas, con un predominio de las viudas, cuando se acredita el estado; las hermanas, algunas viudas y doncellas; y las parientas sin determinar, con un $9 \%, 8,3 \%, 7,6 \%$ y $6,5 \%$, respectivamente.

Compadres y comadres se encuentran muy equiparados, ya que reciben un $2,5 \%$ y $2,8 \%$, respectivamente, de los legados del grupo. Por último, rondando el $1 \%$, encontramos los tios, tías, cuñados, parientes masculinos sin determinar, ahijados, ahijadas y primos.

Como vemos, los legados van más en función de la necesidad y el afecto que del sexo y siempre se procura que queden en la misma línea ${ }^{13}$. A veces se contempla la sucesión del legado y la posibilidad de que fallezca el legatario, en cuyo caso puede pasar a los herederos del clérigo, a los descendientes del legatario, a otra persona, casi siempre un hermano del fallecido, si éste no tuviera descendencia, a la lglesia o a alguna entidad benéfica.

\footnotetext{
12 Porcentaje similar al que Rey Castelao detecta a fines del siglo XVII entre el clero compostelano, un 56,7\%, pero superior al que encuentra Garcia Fernández entre el vallisoletano, 40,7\%. REY CASTELAO, O.: "El clero urbano compostelano a fïnes del siglo XVIl. Mentalidades y hábitos culturales", La Historia social de Galicia en sus ficentes de protocolos. Santiago de Compostela, Universidad, 1981; y GARCIA FERNÁNDEZ, M: Herencio y patrimonio familiar en la Castilla del Antiglo Régimen. Religiosidad, actitudes coleciivas y comportamientos económicos. Valladolid, Universidad, 1995.

"D. Alonso González Barroso, presbítero beneficiado, manda, para el mayor socorro de sus parientes, que dos partes de casa declaradas las gocen alternativamente por tiempo de un año, bien habitándolas, bien alquilándolas, cuatro sobrinas, dos de ellas doncellas y una viuda, hijas de sus hermanos difuntos. Si alguna fallece entrará en su lugar un sobrino varón. A.H.P.C. Sección Protocolos de Alcalá de los Gazules, Libro 140 , folios 22-27.
} 
En ocasiones, los legados serán efectivos al tomar estado el legatario, pretendiendo, de esta forma, que sean más útiles para su porvenir. Por último, se pretende una cierta equidad en lo que a la concesión de mandas se refiere, de forma que cuando los legatarios son hermanos entre sí los legados son idénticos, lo cual se aprecia sobre todo con las mandas de dinero y ganado, siendo más frecuente entre sobrinos y sobrinas, aunque, también, a veces, se advierten preferencias o legados en función del sexo ${ }^{14}$. Sobrinos y sobrinas serán sus principales legatarios mientras que hermanos y hermanas, como veremos, sus principales herederos.

Respecto a los albaceas, el $46,8 \%$ de los mismos está compuesto por los miembros de este grupo. Dentro del mismo, los hombres se erigen en protagonistas frente a las mujeres, algo completamente previsible, si tenemos en cuenta la situación de la mujer en el tipo de sociedad que nos ocupa, relegada a las funciones "propias de su sexo", y su índice de alfabetización'.

Entre los componentes masculinos, aparecen en primer lugar los sobrinos, más de la mitad de los cuales son clérigos, representando el 29,3\% del total de familiares; a éstos siguen, con un porcentaje ligeramente inferior, $26,9 \%$, los hermanos.

Otros miembros masculinos, cuya incidencia es muchos menor, e incluso aneedótica, en algunos casos, son los tíos, todos clérigos, 2,3\%; primos, 1,5\%; cuñados, 1,5\%; hijos $^{16}, 1,5 \%$; compadres, $0,7 \%$; y padres, también $0,7 \%$.

Entre las mujeres de la familia, aparecen, en primer lugar, las hermanas, de las que más de una cuarta parte son doncellas o viudas, con un $22,2 \%$. Es posible que al vivir muchas con ellos fueran sus albaceas ideales, pues conocerían todo lo concerniente a sus bienes, deudas, preferencias por ciertos familiares o vecinos, etc.; a éstas siguen, ya a mayor distancia, las madres, 3,9\%; sobrinas, $2,3 \%$; primas, $1,5 \%$; una tia y una comadre ${ }^{1 ?}$.

\footnotetext{
14 D. Bartolomé Muñoz Morillo, presbitero beneficiado, tiene un sobrino, su ahijado, criado en su casa y que vive en ella, $y$ una sobrina que le asiste. Ambos reciben legados varios pero a él le deja mayor cantidad de dinero y tierras y a ella, por su parte, plata y alhajas. A.H.P.C., Sección Protocolos de Alcalá de los Gazules, Libro 161, folios 66-73.

"I DE LA PASCUA SÁNCHEZ, M. J.:, op. cil., págs. 68-69.

in Se trata de los teslamentos de D. Alonso Jiménez de Zurita, presbitero y Comisario del Santo Oficio en Sevilla, el cual estuvo casado y velado con una vecina de Medina con la que tuvo un hijo legitimo; y de D. Andrés Muñoz de la Vega, clérigo de menores, quien presenta un testamento hecho en virtud de poder por su hijo. A.H.P.C., Sección Protocolos de Alcalá de los Gazules, Libro 144, folios 426-428 y Libro 276 , folios 73,74 .

${ }_{17}$ Entre tos presbiteros del obispado de Coria, los componentes de la familia que aparecen como albaceas presentan los siguientes porcentajes: los sobrinos son albaceas en el $33 \%$ de los casos, los hermanos y hermanas suman el $25 \%$, tios y primos el $7 \%$ y padres el $1 \%$. ARAGÓN MATEOS, S.: "Notas sobre el clero secular en el Antiguo Régimen. Los presbiteros en el obispado de Coria en el siglo XVIII". Hispania Sacra, 89 (1992), 291-334.
} 
En cuanto a la herencia, el $89,2 \%$ de los herederos pertenece al grupo de la familia y allegados, lo que no difiere de la tónica genera $1{ }^{18}$, pues el clérigo pretende que su patrimonio quede dentro de la familia.

En este caso, las mujeres resultan ser las principales beneficiarias, hecho completamente explicable, pues la mujer durante el Antiguo Régimen se encuentra desprotegida y en inferioridad de condiciones con respecto a los hombres, por lo que necesita un determinado patrimonio para vivir con cierto desahogo, unos medios y una seguridad que los bienes de los clérigos le pueden proporcionar. Además, muchas de estas mujeres, hermanas, sobrinas y primas, sobre todo, vivirían con ellos, guardarian sus casas, les asistirian, por lo que se convertitían, como muestra de agradecimiento, en sus principales herederas.

Dentro de las herederas de la familia, las hermanas ${ }^{19}$, una cuarta parte de las cuales son doncellas o viudas, suponen el $37,8 \%$ del total del grupo familiar. A éstas siguen, a cierta distancia, las sobrinas, con un $13,7 \%$. Con porcentajes menores, las madres, 5,7\%; primas, $2,5 \%$; cuñadas, $1,2 \%$; y ahijadas, $0,6 \%$.

Entre los varones de la familia encontramos en primer lugar a los hermanos, con un $19,8 \%$ del total familiar, seguidos de los sobrinos, el $14,7 \%$ de dicho grupo. Con porcentajes mucho menores se encuentran los herederos legítimos: padres, $3,2 \%$; e hijos, $1,2 \%$.

Según se desprende de estos datos, prima el parentesco sobre el sexo, de forma que heredan primero los hermanos y después los sobrinos. Dentro del primer grado, no obstante, impera el sexo y la necesidad del heredero, pues las hermanas vivirian con ellos, principalmente las doncellas y viudas. En el segundo, entre los sobrinos se aprecia una mayor igualdad, ya que el sexo no sería una cuestión preferente, pues destaca ligeramente el porcentaje de los varones.

En líneas generales, impera el principio de igualdad. Suelen ser herederos los hermanos y las hermanas y, en caso de faltar alguno, los hijos de éstos, es decir, sobrinos o sobrinas huérfanos, que ocuparían el lugar de sus padres en el reparto equitativo. Se pretende asi beneficiar a todos los hermanos y sus descendientes por igual. A partir de ahí, una vez que pasamos el grado con el que se tienen verdaderas obligaciones, ya son otro tipo de consideraciones y preferencias, más personales, las

\footnotetext{
* Fid ARANDA MENDÍAZ, M.: El hombre del siglo XVIII en Gran Canaria. El testamento como fuente de investigación histórico-juridica. Las Palmas de Gran Canaria, Universidad, 1993, pág. 189; y REY CASTELAO, O.: op. cit, pág. 502.

${ }^{19}$ La importancia de las hermanas, como en otras zonas, es incuestionable, Vid. REY CASTELAO, O.; op. cit. Y ARAGÓN MATEOS, S.: op. cit., pág. 328.
} 
que se tienen en cuenta, como el cariño, la necesidad, el estado ${ }^{20}$ o la gratitud ${ }^{21}$ hacia ciertos sobrinos, primos o parientes sin determinar. En estos casos es donde se suele detectar la convivencia con otras mujeres de la familia aparte de las hermanas, mujeres solas, en su mayoria, con las que se mantiene una confianza y un afecto muy especiales $^{22}$. La herencia adquiere así su sentido utilitario más pleno, pues servirá para mantener a todas estas personas con las que el clérigo guarda una relación más intensa.

La transmisión del patrimonio queda muy supeditada a las obligaciones y responsabilidades que se tienen para con los miembros de la familia más cercana siguiendo un orden lógico. Estos clérigos viven en un entorno pequeño, rodeados de sus familiares, por lo que sus bienes quedan para ellos.

Por último, en la cláusula relativa a las deudas, los familiares representan el $7,5 \% 0^{23}$ de los acreedores y el 7,3\% de los deudores. Los conceptos de las deudas no se suclen indicar en ninguno de los dos casos.

La limitación de la fuente utilizada nos impide conocer el número de miembros de las familias de estos clérigos ${ }^{24}$. Tampoco sabemos con quiénes vivían, pero a través de las mandas podemos averiguar algo al respecto. De esta forma, advertimos que muchas hermanas, sobrinas y primas vivian con ellos y les asistían. Por otra parte, encontramos una cierta relación entre aquéllos que presentan algún beneficio o cargo importante dentro de la iglesia alcalaína y el número de mandas que presentan, siendo éstas, en su mayoría, para los familiares. El tener

\footnotetext{
2"Así, D. Juan Caballero, presbítero, deja como herederos a 3 hermanas y un hermano, por el mucho amor y cuidado en su enfermedad, con derecho de acrecer, pero si alguno tomase cstado de matrimonio "lo que no espero ejecuten", su parte será para los demás que permanezcan en estado honesto. A.H.P.C., Sección Protocolos de Alcalá de los Gazules, Libro 352, folios 176-181.

"D. Mateo González, presbítero, tiene una sobrina doncella conviviendo con él; aunque tiene más hermanas, ella será su heredera, por cuidarlo. A.H.P.C., Sección Protocolos de Alcalá de los Gazules, Libro 99, folios 152-154.

${ }^{22} \mathrm{D}$. Domingo Muñoz de la Vega, presbítero y beneficiado propio, tiene una vecina acogida de 3 años, criada en sus casas por su prima, que es su heredera y, según se desprende del testamento, vive con él. Su prima administrará los bienes de la niña sin que la justicia secular o eclesiástica se entrometa. A.H.P.C., Sección Protocolos de Alcalá de los Gazules, Libro 70, folios 24-26.

"El clero vallisoletano tiene a sus familiares como acreedores en el $2,38 \%$ de los casos y como deudores en un 4,26\%. GARCÍA FERNÁNDEZ, M.: Los castellanos, la muerte y el más allá en el Antiguo Régimen. Religiosidad, actitudes colectivas y comportamientos económicos. Valladolid, Universidad, 1995, pág. 970. Esta diferencia puede ser debida al contexto en el que se mueven ambos grupos: un entorno rural o urbano evidentemente influye en la relación con la familia.

${ }^{24}$ El tamaño de los hogares de los clérigos del entorno rural gallego se sitúa en torno a las cuatro personas. DUBERT GARCIA, I.: Historia de la familia en Galicia durante la Edad Moderna (15501830). Estructura, modelos hereditarios y conflictividad. La Coruña, 1992, pág. 171.
} 
unas rentas superiores permite a estos clérigos hacer su generosidad más extensiva a los miembros de su familia ${ }^{25}$.

Con objeto de acercarnos al tema, hemos estudiado los que presentan un mayor número de mandas y los que menos, así como el número de familiares que aparecen en las mismas, comparándolo con los herederos que nombran, para llegar a algunas conclusiones al respecto, si no concluyentes, sí, al menos, un poco esclarecedoras.

Si tomamos todos aquellos clérigos que presentan más de 10 mandas, 13 en total, y de ellos extraemos los que acreditan cargos o beneficios, 9 concretamente, observamos que, en primer lugar, la mayoría de los que realizan más legados, algunos en un porcentaje muy elevado ${ }^{26}$, son los que tienen beneficios o cargos importantes dentro de la iglesia alcalaína. En segundo lugar, éstos mismos clérigos dejan la mayoría de sus legados a familiares y, seguidamente, a vecinos, vecinos que no sabemos si son familiares o sirvientes en algún grado o medida, en cualquier caso, personas allegadas a ellos ${ }^{27}$. Por último, 4 de estos clérigos dejan como heredera a su alma.

En definitiva, aquellos clérigos que más legados otorgan son los que presentan un mayor número de familiares en los testamentos y casi un tercio de ellos dejan como heredera a su alma, en un intento de conjugar las solidaridades familiares con sus deberes espirituales. No obstante, ello no implica que éstos sean los que más familiares poseen sino que alrededor đe estos clérigos, con mayor poder adquisitivo, se mueve un número más elevado de parientes, acoge a más gente bajo su protección, ésta se extiende a más familiares. La generosidad, obviamente, está en función de la capacidad económica.

Por otra parte, existen 14 testamentos en los que los testadores realizan solamente 1 ó 2 mandas. De ellos, en 5 ocasiones se deja, al menos, 3 herederos, lo cual parece indicar que a mayor número de herederos las mandas se restringen. El patrimonio a repartir y la necesidad de los herederos, obviamente, también

\footnotetext{
${ }^{25}$ Según Morgado, la familia aumenta a medida de ascendemos en la escala clerical. MORGADO GARCIA, A.: El estamento eclesiástico y la vida espiritual en la diócesis de Cádiz en el siglo XVII. Cádiz, Universidad, 1996, pág. 143.

${ }^{26}$ D. Diego Muñoz de Medina, presbitero beneficiado y Comisario del Tribunal de la Santa Cruzada, realiza 24 mandas. A.H.P.C., Sección Protocolos de Alcalá de los Gazules, Libro 415, folios 8-24.

"Quizás la nota discordante la marca D. Alonso Trujillo y Navas, presbítero, beneficiado propio y Abogado de la Real Chancillería de Granada, el cual presenta 38 mandas, curiosamente sólo 6 son para familiares, el resto las distribuye entre vecinos de Alcalá, en su mayoría mujeres, y de otras localidades. Ignoramos si este clérigo era de otra localidad, pues no declara su naturaleza, o si éstos vecinos son parientes o sirvientes suyos. Deja como heredera a su alma. A.H.P.C., Sección Protocolos de Alcalá de los Gazules, Libro 17, folios 51-75.
} 
inciden ${ }^{28}$. Asimismo, cuando estas escasas mandas no van a miembros de la familia, los herederos son parientes más lejanos, lo que puede implicar la inexistencia de familia cercana.

En este mundo de solidaridades y responsabilidades familiares, se hacen cargo de la manutención de algunos miembros de la familia ${ }^{29}$, actúan como tutores y curadores de sobrinos, actividad que realizan con escrupulosidad y, en muchas ocasiones, renunciando a cualquier tipo de compensación $\mathrm{n}^{30}, \mathrm{y}$ administran los bienes familiares y las herencias que quedan proindivisas, muchas veces porque existe una convivencia entre los herederos ${ }^{31}$, tratando de ser lo más equitativos y justos posibles ${ }^{32}$; aunque, en más de una ocasión, consideran tales bienes como propios en pago de los gastos que por sus familiares han realizado ${ }^{33}$, 0 les otorgan legados menores en compensación por los beneficios aportados con anterioridad ${ }^{34}$. Al administrar bienes y legados de sus familiares pretenden que éstos no decaigan, que sean rentables y den frutos, realizando las transacciones y actividades económicas que creen más adecuadas a fin de que las personas admi-

${ }^{28}$ D. Juan Caballero, presbítero, presenta sólo un legatario, su hermano, que está en mejores condiciones, los demás, más pobres, serán sus herederos. A.H.P.C., Sección Protocolos de Alcalá de los Gazules, Libro 352, folios 176-181,

${ }^{29}$ D. Bartolomé Navarro de Medina, presbítero, tiene entre sus deudores a un vecino que le debe 7 ducados y medio de la renta de un buey, para cuya cuenta le ha pagado unos zapatos suyos, dos pares de su sobrino, unos de su mujer y otros de su hijo. A.H.P.C., Sección Protocolos de Alcalá de los Gazules, Libro 145, 3 folios.

Io D. Diego Jiménez de Zurita, clérigo de menores, fue curador de su sobrino durante 28 meses realizando dirante ese tiempo una serie de gastos en pleitos a su nombre. Ordena que si su sobrino aprobase las cuentas dadas no se le cobren las décimas que se le deben dar como tal curador ni los gastos efectuados, pues, en tal caso, le hace gracia por vía de legado. A.H.P.C., Sección Protocolos de Alcalá de los Gazules, Libro 340, folios 58-68

"D. Francisco Manzano y Ortega, presbitero, y su hernuana fueron, junto con otros familiares, los herederos de su tío, "y la parte que de dicho caudal nos tocó a ambos lo percibi yo todo, quien lo he estado manejando todo junto, y sin separar cosa alguna, por estar como está y ha estado en mi compañia la dicha Dña. Inés, mi hermana". A.H.P.C., Sección Protocolos de Alcalá de los Gazules Libro 276, folios 29-33.

${ }^{12}$ D. Diego Morillo Bañales, presbítero beneficiado, administra el caudal que quedó por muerte de su madre y que ha estado proindiviso entre sus otros tres hermanos. Antes del fallecimiento de la misma, su hermana, Dña. Leonor, tomó estado, para lo cual fue dotada con una serie de bienes. Es su voluntad que si ella o sus hijos quisieran entrar en dicho caudal se hayan de igualar primero los otros tres hermanos $y$, si sobrase alguna cosa de dichos bienes, entre en parte de ellos dicha Dina. Leonor. A.H.P.C., Sección Protocolos de Alcalá de los Gazules, Libro 186, folios 164-168.

${ }^{3 i}$ A D. Lotenzo Bernardo de Ortega, presbítero, su padre le dejó un poder para que hiciera testamento comunicándole sus deudas, las cuales ha pagado de su caudal, por lo que considera la casa familiar como suya. Si sus hermanos creen tener derechos sobre ella o sobre otros bienes de su padre y madre como legítima, deberán partir también todos los gastos que e] otorgante ha hecho por razón de deudas pagadas, préstamos realizados a sus hermanos, alquileres de casas, etc. A.H.P.C., Sección Protocolos de Alcalá de los Gazules, Libro 63, folios 4-7.

${ }^{14}$ D. Lorenzo Bernardo de Ortega, presbitero, deja sólo 100 reales de vellón a sus sobrinos porque en vida dio a su madre, su hermana, todo cuanto pudo. A.H.P.C., Sección Protocolos de Alcalá de los Gazules, Libro 63, folios 4-7. 
nistradas puedan gozar de los mismos y de sus rentas en las mejores condiciones posibles. No obstante, no siempre se consiguen los mejores resultados ${ }^{35}$.

Por último, asumen las cargas y deudas de éstos, a veces en una cuantía considerable. Ningún ejemplo tan claro, entre todos los que aparecen, como el de D. Diego Muñoz de Medina, presbítero, beneficiado y Comisario del Tribunal de la Santa Cruzada, en relación con su hermano D. Cristóbal, también presbítero, el cual, a causa de diversos litigios y pleitos, había sufrido numerosos gastos a los que, en más de una ocasión, hizo frente D. Diego.

Según nos indica en su testamento, D. Diego se comprometió, como subsidiario con el Cabildo de la Villa, a dar cada año 6000 reales hasta la extinción de un débito de 17000 del que su hermano era responsable por una administración que llevaba. Assimismo, en una testamentaría de la cual también era responsable dicho hermano, algunos de los miembros de la familia del testador habian recurrido al Sr. Provisor y Vicario General de Cádiz, para hacer cargos contra él sobre la distribución y cuentas de la misma "por lo cual padecimos muchos dispendios en la Audiencia Episcopal". En otro momento, D. Cristóbal, junto con otro presbítero de Alcalá, fue Diputado de un pleito por la mala utilización de caudales del pósito de la Villa. Ambos fueron afianzados de calumnia en la cantidad de 1000 ducados, cantidad que fue aprontada por un tercero. El litigio subsiguiente fue costeado de su propio caudal. Cuando falleció D. Cristóbal, D. Diego, como heredero, debía pagar su parte proporcional de los 1000 reales. No obstante, el pleito continuó y le fue favorable, por lo que la obligación quedó anulada. Por último, en otro pleito que se suscitó por varios hacendados sobre la destrucción y menoscabo que padecían los montes de la Villa también fue nombrado diputado D. Cristóbal, quien debía dar su parte como interesado que era en dicha queja para el seguimiento de las diligencias judiciales. Como heredero de su hermano le correspondía pagar dicha parte "de los muchos gastos que tuvieron en esta diputación, que estoy en que ascendieron a 22000 reales" 36.

Estas funciones realizadas con los miembros de la familia cobran especial relevancia en el caso de las mujeres. Ante todo se pretende que la protección de que gozaban mientras él vivía la sigan manteniendo después de su muerte, sobre todo aquellas personas que por sus circunstancias personales no pueden valerse

\footnotetext{
${ }^{3}$ D. Nicolás Antonio González de Brito, presbítero y prebendado de la Santa Catedral de Sevilla, quedó encargado de satisfacer un legado a 1000 ducados a sus tres sobrinas, y para ello los situó sobre un horno, Los interesados aún no han cobrado cosa alguna "porque tiene entendido que dicho homo, después de los censos, no valdrá los dichos 1000 ducados", lo declara para descargo de sus conciencia, y para que de su caudal se satisfaga el dinero. Sección Protocolos de Alcalá de los Gazules, Libro 340, folios 37-40.

${ }^{36}$ A.H.P.C., Sección Protocolos de Alcalá de los Gazules, Libro 415, folios 8-24.
} 
por sí mismas. Éstas serán objeto de una atención especial ${ }^{37}$. El acogimiento, la tutela y salvaguardia sobre las mujeres a su cargo hace que sean las personas más importantes para ellas, las que mayor potestad y autoridad moral tienen sobre las mismas. La convivencia con parientas femeninas, en especial hermanas, sobrinas y primas queda atestiguada en varios testamentos y se intuye en otros. Estas mujeres, que saben todo lo concerniente a sus bienes y a su casa, pues la guardan y cuidan, serán, en muchas ocasiones, sus herederas y, cuando no, recibirán importantes legados.

\section{Sirvientes}

Dentro de este grupo incluimos a los sirvientes propiamente dichos, a los acogidos y a los esclavos. Tales personas viven con ellos y forman parte de su estructura familiar ${ }^{38}$, por lo que se benefician, en gran medida, de su generosidad.

Dicho grupo recibe el $10,2 \%$, del total de los legados ${ }^{39}$, siendo las principales beneficiarias las asistentas, las cuales representan el 34,6\% del total del grupo, a las que los clérigos tratan de agradecer, por medio de estas dádivas, el trabajo y asistencia prestados y de aliviar, en la medida de lo posible, la pobreza que muchas padecen. Este porcentaje, no obstante, podría sufrir alteraciones tanto al alza como a la baja, pues es muy probable que muchas de las vecinas que aparecen con esa sola especificación también sirvieran a los clérigos, si no permanentemente, sí con cierta regularidad; y lo mismo cabe decir de las hijas de tales asistentas, las cuales, incluso, vivirían con ellas en la casa del clérigo. Por el contrario, algunas de estas mujeres también podrían ser familiares, en algún grado o medida, aunque no se indique en los testamentos, por lo que deberían ser incluidas en el grupo de la familia, incidiendo, de esta forma, a la baja en dicho porcentaje.

\footnotetext{
${ }^{37}$ D. Diego de Viera Márquez, presbítero y beneficiado, tiene en su casa y compañía, a sus expensas, a su prima y a su sobrina doncella lullida, también sobrina de su prina. Cuando fallezea él y su prima, la sobrina, si quiere, se puede retirar a un cuarto aparte del Hospital que funda, con comida, cama y vestido separado, como corresponde a su calidad, de por vida, con las rentas del Hospital, y, si fallece sin medios, la obra pía le costeará un entierro de medias honras. A.H.P.C., Sección Protocolos de Alcalá de los Gazules, Libro 317, folios 92-107.

${ }_{38}$ Es lo que Dubert llama una familia de cstructura indeterminada, en la cual sus miembros pueden estar unidos por lazos de sangre o no. De esta forma, corresidencia y parentesco son elementos que definen la familia del clérigo. DUBERT GARCÍA, I.: Los comportamientos de la familia urbana en la Galicia del Antiguo Régimen. El ejemplo de Santiago de Compostela. Santiago de Compostela, 1987, pág. 39.

30 Algunos puntos menos que el registrado para los criados del clero vallisoletano. GARCíA FERNÁNDEZ, M.: Herencia, pág. 154.
} 
Estas asistentas recibirán legados varios: ganado, menaje, ropa, dinero..., atendiendo a su condición ${ }^{40}$, a cambio de continuar asistiéndoles hasta que fallezcan.

Dentro de los acogidos, personas que se han criado en sus casas desde pequeños, bajo su protección y cuidado, posiblemente hijos de sirvientes o vecinos necesitados, ahijados suyos en más de una ocasión y que muy probablemente le sirvieran en compensación de su acogimiento; las mujeres reciben el $23 \%$ de los legados del grupo de los sirvientes y los hombres el 9,6\%. Las preferencias de estos clérigos parecen claras: la situación de la mujer en el Antiguo Régimen hace que este tipo de comportamientos no sean extraños. El acogimiento genera cariño y ésto se ve reflejado en las mandas; nos movemos en un mundo de agradecimientos y compensaciones, de servicios a cambio de protección. Se piensa en el futuro de los acogidos, en su crianza, hasta en su posible fallecimiento y la regulación de su entierro. Aunque, además del cariño, agradecimiento o compensación también se deja entrever a través de estas mandas la necesidad que tienen estos hombres de agradar a Dios por medio de las mismas, una obra de caridad cristiana que será premiada en el cielo. Así, D. Francisco de Oliva y Cano, justifica el legado que le piensa hacer a una niña expósita, criada en su casa, "atendiendo al obsequio que hará al Todopoderoso de señalarle algunos bienes para su alimento y que asi puedan acabarla de criar, vestir y alimentar..." ${ }^{\prime 41}$.

El vínculo que se crea entre un clérigo y sus protegidos será para toda la vida, pues les seguirá beneficiando incluso después de tomar estado, aunque es muy probable que después de este hecho los acogidos siguieran asistiendo al clérigo y continuasen en sus casas, esta vez con toda su familia ${ }^{42}$.

Los sirvientes varones, capataces, yeguarizos, asistentes, etc., representan el $17,3 \%$, de las mandas del grupo. Al igual que ocurría con las asistentas, los hijos varones de los sirvientes también podrían, en alguna medida, servir a los clérigos.

Por último, los esclavos, muy pocos entre los clérigos de Alcalá, perciben el $5,7 \%$, mientras que las esclavas el $9,6 \%$ de las mandas otorgadas. Éstos reciben una gran variedad de legados, aparte de su libertad: grano, ganado, tierra, cuartos vitalicios en sus casas, ropa, etc., pues deben comenzar una nueva vida y tener sus necesidades cubiertas. En alguna ocasión encontramos, incluso, varias genera-

\footnotetext{
4) D. Juan de Cárdenas y Montes, presbítero beneficiado, manda un ajuar, "para una casa como pobre", a su asistenta doncella. A.H.P.C., Sección Protocolos de Alcalá de los Gazules, Libro 1, foljos 11-21.

${ }^{4}$ A.H.P.C., Sección Protocolos de Alcalá de los Gazules, Libro 205, folios 113-120.

${ }^{42}$ D. Pedro Collado Cortegana, presbítero, beneficiado, cura y Vicario, deja a una vecina casada y a su marido 1000 reales de vellón por haberla criado. A.H.P.C., Sección Protocolos de Alcalá de los Gazules, Libro 132, folios 45-57.
} 
ciones de esclavos sirviendo a estos clérigos, lo cual parece indicar que llevan toda la vida con ellos ${ }^{43}$.

Las asistentas aparecen como herederas en 3 ocasiones, el 1,7\% del total de herederos y como albaceas en 2, lo que supone el 0,7\%. Aparte del agradecimiento o la necesidad, en alguna ocasión el recibir la herencia lleva aparejado una serie de obligaciones ${ }^{44}$.

Respecto a las deudas, este grupo representa el $8,8 \%$ de los acreedores, con deudas debidas a salarios, principalmente, mientras que como deudores aparecen en el $1,3 \%$. En este caso el concepto de las mismas no suele especificatse.

\section{Vecinos}

El grupo de los vecinos se beneficia del 33,3\% del total de los legados ${ }^{45}$. El contexto rural en el que se desenvuelve la vida de estos hombres, el apego a la tierra y a sus gentes, el arraigo, hacen que la vecindad sea vivida de una forma mucho más intensa que en el entorno urbano. No obstante, también pensamos que muchos de esos vecinos, a los que hemos catalogado con esa sola denominación al carecer de otros datos, pudieran ser parientes en algún grado, en unos casos, y sirvientes, en otros, lo cual se deja entrever en algunos testamentos ${ }^{46}$.

Dentro de este grupo, las vecinas perciben el 53,5\% de los legados del mismo, mientras que los vecinos el $37 \%$. Los vecinos suelen recibir dinero, sobre todo las vecinas doncellas a viudas, en cantidades que oscilan los 100 reales de vellón; ropa, como mantos y sayas; ganado, una o dos cabezas de ganado vacuno; y muebles y menaje en general.

La presencia de estos vecinos en la cláusula de los albaceas es, obviamente, mucho menor, representando tan sólo el 9,6\% de los albaceas del clérigo, con un

\footnotetext{
"D. Juan Gómez Correa, presbitero, posee tres esclavos, abuela, madre e hijo, a los que deja legados varios. A.H.P.C., Sección Protocolos de Alcalá de los Gazules, Libro 296, folios 65-69 y folios 73-77. ${ }^{44} \mathrm{D}$. Tomás Joseph Vela Castaño, presbítero, cura y colector, deja como heredera a su asistenta, con la explicita obligación de asistir, cuidar y alimentar a su hermano y a su prima, que también viven en su casa. A.H.P.C., Sección Protocolos de Alcalá de los Gazules, Libro 229, folios 285-292.

${ }_{45}$ Porcentaje muy superior al que García Fernández detecta entre el clero vallisoletano, el cual es del 8,9\%. GARCÍ A FERNÁNDEZ, M.: Herencia, pág. 154.

45. Fernando Costilla Cordero, presbítero, lega a una vecina viuda 20 ducados "por lo bien hecho". Como él, D. Francisco Manzano y Ortega, presbitero, manda que su vecina viuda y sus 3 hijos permanezcan en su casa un año y si no encuentran otro sitio les lega una atahona. A.H.P.C., Sección Protocolos de Alcalá de los Gazules, Libro 275, folios 169-173; y Libro 306, folios 95-98.
} 
predominio de los varones casi absoluto: frente a 24 vecinos encontramos tan sólo 3 vecinas. En la de herederos, por su parte, no constan.

Finalmente, en el apartado de las deudas sí que presentan un protagonismo indiscutible, pues suponen el $52,8 \%$, de sus acreedores y el $81,9 \%$ de sus deudores. Tanto unas como otras se deben a arrendamientos y préstamos; arrendamientos de tierras en las que cultivan, en las acreedoras, y de las casas de sus capellanías y memorias o de sus animales en las deudoras. Este hecho indica que los clérigos alcalínos estaban muy inmersos en los circuitos económicos de su pueblo, manteniendo con sus vecinos las operaciones propias de una economía de base agropecuaria, además de las relacionadas con su condición clerical.

\section{Compañeros de grupo}

Los compañeros del clérigo perciben el $2,7 \%$ del total de los legados ${ }^{47}$. Porcentaje bajo pero lógico, ya que el clérigo pretende beneficiar en mayor medida a aquéllos con los que tiene una cierta obligación. Este grupo se muestra idóneo, no obstante, para realizar otro tipo de menesteres, como la función de albaceazgo, por ejemplo, donde muestra un papel relevante, apareciendo los compañeros del clérigo como albaceas en el $42,3 \%$ del total de los mismos. La confianza en los miembros del propio estamento está sustentada en su mayor capacidad para solucionar todas aquellas cuestiones relacionadas con la partición de sus bienes; las decisiones tomadas serán incuestionables. No olvidemos que este bajo clero, aunque posea unas condiciones culturales muy mediocres es el referente cultural de un pueblo cuyo nivel de alfabctización es muy bajo. Éstos compañeros serán también una posible opción en caso de que los albaceas familiares elegidos fallezcan, sustituyéndolos, en este caso, los beneficiados o curas más antiguos, los curas de las iglesias de la Villa o el Sr. Vicario.

Por otra parte, el número de albaceas clérigos, tanto familiares como no familiares se eleva a 141 , es decir, el 52,4\% del número total de albaceas.

\footnotetext{
${ }^{47}$ Porcentaje bastante inferior al que García Fernández registra para las donaciones del clero vallisoletano al propio estamento, las cuales se dan en un 10,7\%. GARCíA FERNÁNDEZ, M.: Herencia, pág. 154 .
} 
Por último, respecto a las deudas, dicho grupo representa el $10 \%$ de los acreedores ${ }^{48}$ y el $6,6 \%$ de los deudores. Los motivos de las deudas, cuando aparecen, son muy variados: censos, préstamos, misas dichas por ellos, etc.

\section{A MODO DE CONCLUSIÓN}

De todo lo anteriormente expuesto podemos sacar algunas conclusiones:

Respecto a la familia del clérigo, vemos que ésta es muy amplia y está compuesta por todas aquellas personas que viven en su hogar, bajo su mando y protección. A través de determinadas referencias en los testamentos acerca de la convivencia, comprobamos una presencia destacada de mujeres en su casa, en particular, hermanas, sobrinas y primas. Las mujeres de la familia que viven con ellos también les asisten, lo cual coincide con los resultados de los estudios realizados en otros puntos de nuestra geografia ${ }^{49}$. Sobre estas personas el clérigo ejerce su autoridad y tutela y serán sus herederas y las receptoras de los legados más importantes, en la mayoría de los casos, conjugando así gratitud y obligación.

Su posición social y económica superior y las características del medio en el que se desenvuelve ${ }^{50}$ harán que en este entorno familiar el clérigo, como en otras zonas $^{51}$, se convierta en protector de los desvalidos, en particular de las mujeres ${ }^{52}$, lo que explicaría la composición familiar de su hogar, tutor y curador de sus sobrinos, administrador de los bienes familiares, depositario de legados y herencias y en el padrino idóneo para unos ahijados muy necesitados. No obstante, dado que el entorno familiar del clérigo es muy amplio, a menudo éste se presenta como el padrino de los hijos de sus sirvientes y esclavos y extiende su protección hacia la mujer necesitada, a las asistentas, mozas acogidas y vecinas.

\footnotetext{
${ }^{48}$ Porcentaje similar al detectado entre el clero ovetense, pero muy inferior al que presenta el clero vallisoletano a mediados del XVIII. Vid. LÓPEZ LÓPEZ, R. J.: "Aproximación al clero urbano ovetense (1751-1790)", Cuadernos de Investigación Histórica, 11 (1987), 111-129; y GARCIA FERNÁNDEZ, M.: Los castellanos, pág. 970.

4v Vid. ARAGÓN MATEOS, S.: op. cit., y DUBERT GARCIA, I.: Historia.

"Según Dubert García, la función social de acogida de los más desfavorecidos mantiene una relación inversamente proporcional al grado de desarrollo urbano. En otras palabras, cuanto más grande es la ciudad, mayor es la desnaturalización del carácter asistencial de sus hogares. DUBERT GARCIA, I.: Historia, pág. 174.

${ }^{51}$ Ibídem, pág. 172.

${ }^{52}$ Morgado García ha demostrado entre el clero gaditano que en la función de recogida, tanto de parientes como de extraños en situación desamparada, predomina abrumadoramente el elemento femenino. MORGADO GARCÍA, A.: op. cit., pág. 145.
} 
Según vemos, las solidaridades familiares se muestran prioritarias. Las obras de caridad deben hacerse, antes que nada, con los miembros de la propia familia y con todos los conocidos ${ }^{53}$. No existe un sentimiento caritativo hacia los pobres o los necesitados en general, todo es más personalizado, esos pobres de la Villa son sus vecinos, sus familiares, sus sirvientes, y a ellos lega sus bienes.

El clérigo rural está inmerso en un mundo de redes familiares que afecta al resto de la población campesina ${ }^{54}$. El clérigo es un elemento más en el abigarrado mundo rural de relaciones sociales y mantiene su propia estrategia respecto a su familia, para perpetuarla y mantenerla en un determinado status, el que él le proporciona. Transmite su patrimonio de la manera más equitativa posible, 10 reparte de forma que todos se beneficien. Este status, no obstante, no debemos entenderlo como referido a riqueza, sino más bien a posición o condición. Se pretende que la familia del clérigo siga siendo la familia del clérigo, que continúe manteniendo en el pueblo la posición que le caracterizaba mientras él vivía, que permanezca protegida. Siguiendo con esta idea, el hecho mismo de introducir a los sobrinos en el propio estamento o de promocionarlos de alguna manera, algo muy común entre los clérigos, no iría encaminada únicamente a que dicho sobrino obtuviera los beneficios inherentes al estado, que también, sino que toda la familia se siguiera beneficiando de ellos. Estos sobrinos representarian el relevo de los tíos en esa asunción de funciones que en su mayoría poseen: administradores, tutores, protectores de la mujer, depositarios, fideicomisarios, etc. No obstante, ésto es sólo una idea que apuntamos, para lo cual tendríamos que seguir la trayectoria de dichos sobrinos.

Respecto a los sirvientes, éstos, a diferencia de lo que ocurre en otros escalones de la jerarquía eclesial, representan una ayuda, no un símbolo de prestigio ${ }^{55}$, lo que repercute necesariamente en el tipo de relación laboral establecida. Dicha relación laboral, en este caso, está basada en la ayuda y asistencia, no en la ostentación, por lo que existe una mayor familiaridad con los miembros del

\footnotetext{
${ }^{53}$ Así, D. Francisco de Oliva y Cano funda una Obra Pía, pero advierte que "y porque puede suceder" sobreviva a mi mi hermano D. Sebastián y morir en estado deplorable... mando que en primer higar a dichas limosnas se haga la de socorrer a mi hermano en cuanto necesite en sus enfermedades $y_{\text {. }}$ muriendo, se le haga un oficio de medias honras y se le digan 20 misas rezadas a 3 reales de vellón "A.H.P.C., Sección Protocolos de Alcalá de los Gazules, Libro 268, folios 21-31.

${ }^{54}$ Según García González, cada vez es más fuerte la tendencia a presentar el estudio de la familia en términos de red. Una tendencia que se justifica plenamente en el caso de la familia campesina, dado que la sociedad rural es una sociedad jerarquizada que tiene en las redes familiares su base más sólida para reproducir esta jerarquía. GARCÍA GONZALEZ, F.: "Historia de la familia y campesinado en la España Moderna. Una reflexión desde la historia social", Revista Studia Histórica, vol. 18, (1998), págs. 135-178.

"En los hogares del clero capitular gallego los criados funcionan con un criterio de diferenciación social, incluso dentro del ámbito eclesial. El número de sirvientes está en relación con los ingresos obtenidos. DUBERT GARCIA, I.: Historia, págs. 172-173.
} 
servicio y una mayor dependencia respecto a ellos. Todos dependen de todos para sobrevivit.

En cuanto a sus vecinos, el hecho de pertenecer a un grupo privilegiado no les impide mantener con ellos un contacto muy importante. La dimensión popular del bajo clero se advierte de forma más intensa en el mundo rural, donde las diferencias entre unos y otros se atenúan mucho más. Esta dimensión puede ser debida a dos causas principales: por una parte, el entorno rural en el que se desarrolla su vida genera unas características propias en la relación, una cercanía y familiaridad con los vecinos que en el entorno urbano no se dan; $y$, por otra, su status clerical en sí, es decir, su condición de bajo clero, extraído del pueblo, más llano y accesible, con un alto porcentaje de individuos nacidos en la localidad y que se encuentran rodeados de toda o gran parte de su familia, económica y culturalmente en condiciones similares a las del resto de sus vecinos, lo que hace que se encuentre en una situación de igualdad respecto a ellos. Estos dos hechos condicionarían su vida y sus relaciones.

Por último, la relación con sus compañeros de grupo, aunque también importante, se encuentra un tanto eclipsada por la que mantiene con familiares, sirvientes y vecinos. A diferencia de otras zonas ${ }^{56}$, en las que prevalece el vínculo estamental sobre el familiar para el albaceazgo, el clero alcalaíno se nos muestra más unido a su familia que a sus compañeros de grupo. La familia se va imponiendo y actúa en escenarios nuevos, y más aún en lugares más cerrados y endogámicos. No obstante, el papel de los compañeros de grupo, aunque inferior, seguirá siendo destacado entre sus albaceas por dos motivos principales: capacidad y confianza, y esto último sólo se puede obtener de un trato continuado y una indiscutible afinidad.

En resumen, nos encontramos con un clero popular, unido a su tierra y a su gente, que guarda con todos los que pueblan su entorno una relación muy fluida y profunda, que presta una especial atención a la familia porque vive rodeado de ella en un núcleo pequeño, a sus sirvientes porque hay una dependencia mutua, a sus vecinos porque los conoce desde siempre y a sus colegas porque confía en ellos.

${ }^{36}$ Vid LÓPEZ LÓPEZ, R. J.: op. cit, pág. 118, y ARANDA MENDÍAZ, M,: op. cit., pág. 198. 